\title{
Child, Parent, and Play - An Insight into These Dimensions Among Children with and without Receptive Expressive Language Disorder Using Video-Based Analysis
}

\author{
Megha Mohan' \\ Gagan Bajaj' \\ Apramita Deshpande (iD) ${ }^{2}$ \\ Malavika Anakkathil Anil ${ }^{1}$ \\ Jayashree S Bhat' \\ 'Department of Audiology \& Speech- \\ Language Pathology, Kasturba Medical \\ College, Mangalore, Manipal Academy of \\ Higher Education, Manipal, Karnataka, \\ India; ${ }^{2}$ Wabi Sabi Speech and Language \\ Clinic, Vadodara, India
}

Correspondence: Gagan Bajaj Department of Audiology \& SpeechLanguage Pathology, Kasturba Medical College, Mangalore, Manipal Academy of Higher Education, Manipal, Karnataka, India

Tel +9l-988646I35I

Email gagan.bajaj@manipal.edu
Purpose: Language development in children aged 3-6 years is shaped by their pre-linguistic abilities, communication patterns and play behaviors along with parental communicative roles. Little is known about how these aspects are distributed among children with receptive expressive language disorder (CWRELD) in comparison to typically developing children (CWTDL). The present research explores these differences between the two groups using a video-based analysis with a belief that an understanding of these aspects may facilitate ageappropriate speech and language acquisition in children with language delay.

Methods: A video-based analysis of parent-child interactions was carried out for 10 children each with receptive expressive language disorder and typical language development, respectively. The two groups were compared for the child's turn-taking skills, eye contact span, autonomous instances, communication patterns, play behaviors and parental communication roles.

Results: Children with receptive expressive language disorder exhibited significantly fewer proportion of turns and autonomous instances along with a greater proportion of eye contact to objects than the parent. Majority of the children with language delay were at the "Requester" or "Early communicators" stage and demonstrated either "Exploratory" or "Functional play" behaviors. Most of the typically developing children were at the "Partner stage" of communication and exhibited "Functional", "Constructive" or "Symbolic Play". Parents of children with language delay mostly exhibited "Helper" type communicative roles while parents from typically developing groups showed "Partner" type communicative profile.

Conclusion: A quantitative planning and monitoring of pre-linguistic skills, determination of communicative patterns and play behaviors is important for clinicians working with children having a language delay. Assessing and modifying parental communicative roles are also crucial. Understanding the distribution of these research variables among CWRELD in comparison to CWTDL may help clinicians in planning precise treatment goals, monitoring specific linguistic progress, ensuring better parental participation and delivering better outcomes during language therapy.

Keywords: receptive expressive language disorder, pre-linguistic skills, communication stages, play behaviors, parental communication roles, parent-child interaction

\section{Introduction}

Childhood entails human development across various domains and is enriched with factors that promote this advancement. Optimal speech and language development during childhood is influenced by the interaction between the development of 
parent-child interactions, pre-linguistic skills and trajectory of play development. ${ }^{1,2}$ An increased parent-child interaction is predictive of a child's vocabulary development, early literacy skill development, ${ }^{3}$ cognitive as well as socio-emotional development. ${ }^{4}$ Pre-linguistic skills are considered to be an important determinant in predicting language outcomes in children during the developmental phase in childhood. ${ }^{5}$ While play interactions provide a perspective for language learning and are believed to reveal the child's cognitive skills. ${ }^{6}$

\section{Parent-Child Interactions}

Language comprehension and the skill to communicate is a significant achievement during early childhood which is facilitated by parent-child interactions in the initial years. ${ }^{1}$ Parent-child interaction builds an interpersonal environment, which sets the stage for either promoting or hampering optimal speech or language development. ${ }^{7}$ A plethora of research explains the importance of parent-child interaction in the development of language,${ }^{8-10}$ literacy, ${ }^{11}$ phonological awareness, ${ }^{12}$ emotional regulation ${ }^{13}$ and cognitive development. ${ }^{14}$ According to Sussman, ${ }^{15}$ whenever the parent and the child interact, they work together in response to each other. This forms the basis of successful two-way communication. Communication gets started every time the parent and the child interact and develop a connection. The child now becomes an active part of a social system and the most critical social structure in a child's life is the family.

\section{Communication Roles Played by Parents}

Parents play a vital role in optimal speech and language development. Parenting studies have consistently associated differences in parenting with variations in child and adolescent development to identify optimal parenting. ${ }^{16-18}$ The role of parents could be a benefit but also harmful for self-esteem, ${ }^{16}$ empathy ${ }^{19}$ or internalization of social values. ${ }^{20}$ Parenting style could be described as parental attitudes as well as behaviors that are mostly used by parents to manage the behavior of their child. This is often assessed by the patterns of responsiveness, punishment, control and warmth. Certain studies have classified parenting roles as authoritative, authoritarian, indulgent and neglectful. ${ }^{16,21}$ Some other studies, specifically in the context of communication, like Sussman ${ }^{15}$ identified four roles, which are usually played by parents as they interact with their children. These include the Partner role, the Helper role, the Cheerleader role and the Do-Not-Disturb role. In the Partner role, the parents and children play games together with each other. Here, parents do not make communication goals very obvious but they take optimum communicative turns and be supportive partners in facilitating desirable communication patterns in the child. In the Helper role, a parent does everything for the child to help him/her communicate when he/she is having a hard time communicating. In the Cheerleader role, the parent appreciates, encourages and rewards every effort by the child in comprehending others and expressing their needs. In the Do-Not-Disturb role, since the child lacks interest in interaction and rarely demands parental attention, parents do not make optimum efforts in initiating any sort of communication with their children. Based on the above profiles, the partner role played by a parent is a more mature and desirable communication model wherein a fine balance between communication opportunities, modeling and reinforcement exists.

\section{Communication Stages of Children}

The present study divides children into four stages based on the child's communication ability with his or her immediate surroundings based on the book by Sussman. ${ }^{15}$ These are the Own Agenda Stage, the Requester Stage, the Early Communicator Stage and the Partner Stage. Though not all children pass through all the four stages in any specific order, many tend to start at the Own Agenda stage, and progress through the Requester and Early Communicator stages, ultimately reaching the Partner stage as their age progresses. A child at the Own Agenda Stage does not understand how he/she can influence people around him/her by targeting an idea directly at them, which makes their communication predominantly pre-intentional. Their interactions with others are usually brief and minimalistic interactions with other children. Parents discern how they are feeling by observing their gestures, body movements, smiles and screams. In the Requester Stage, the child begins to realize that his/her actions can affect others. They start communicating their needs with parents by pulling or leading them towards objects, areas or games they enjoy. In the Early Communicator Stage, the child's communication lasts longer and becomes more intentional. They may begin to repeat some things that they hear to communicate their needs with others. Slowly the child starts a two-way interaction by pointing at things that he/she wants to show his/her parent. In the Partner Stage, the child becomes a more effective communicator. The child begins simple 
conversations confidently in a familiar environment but might struggle in an unfamiliar environment. Although children can communicate about their interests in everyday situations, they resort to memorized words or phrases when they have trouble grasping the rules of conversation. ${ }^{15}$ While not all children pass through these stages, some tend to have characteristics from several stages and do things differently depending on the individuals they interact with, the circumstances they are in and their exceptional personalities. Similar classification systems have also been used in some other studies. ${ }^{22-24}$ For instance, a recent study classified the communication stages of children as Discoverer, Communicator, FirstWord user and Combiner which is a modified and parallel depiction of the milestones described in the classification system by Sussman. ${ }^{15}$

\section{Pre-Linguistic Skills}

Pre-linguistic communication is predominantly non-verbal means of communication used by children which includes gestures, vocalizations, eye-gaze and expressions. ${ }^{5}$ Prelinguistic skills develop before linguistic communication and are meaningful and purposeful, however these do not serve as a symbolic system (language). This first stage of language development forms an essential building block and is desirable for efficient communication. Even before the child learns to speak, the child learns to communicate his/her needs through pre-linguistic skills. Pre-linguistic skills may be used intentionally to communicate their needs or unintentionally to do things without communicating on purpose. These typically develop around 9-15 months of age and establish the foundation for language, ${ }^{25,26}$ social and emotional development. ${ }^{27}$ Turntaking is a salient pre-linguistic skill that lays a foundation for communication skills as well as self-regulation abilities in children, thereby contributing to later language development. ${ }^{28}$ Children learn to understand different personal perspectives and viewpoints while participating in turn-taking. ${ }^{29}$ Another important pre-linguistic skill is eye contact and as a part of normal development, children involve in contact with their parents. ${ }^{30}$ The eye gaze between the object of interest, the parent and the child is considered to be crucial for language acquisition. ${ }^{31}$ The interaction between a child, parent and the ongoing event enables the child to establish pre-linguistic behaviors to initiate, respond and maintain the ongoing events of shared experiences. ${ }^{32}$ Reduced or unfitting eye contact is considered a major discrepancy in children with developmental disabilities. ${ }^{30}$ Lee and Schertz ${ }^{33}$ observed that children with autism exhibited a relationship amid turn-taking and joint attention during an intervention based on parentchild interactions and found that joint attention and turntaking skills positively correlated with each other.

\section{Play Behaviors}

Play is a personally directed, intrinsically motivated activity that is freely chosen. Different types of play, like pretend play and sensorimotor play influence a child's early cognitive development while more advanced types of play like thematic play affect the development of problem-solving and reasoning skills in children. Apart from this, play also influences comprehension and expression of language. Researchers have categorized play into different types based on several considerations. Smilansky ${ }^{34}$ categorized play into four types, ie, constructive play, functional play, dramatic play and games with rules. Researchers have given a comprehensive outline for preschool play types as constructive object play, functional object play, rough and tumble play, exercise play and symbolic play. ${ }^{35}$ It is also divided into symbolic play, physical play, pretend play, closing thoughts, play with objects and rule-based games. ${ }^{36}$

A high correlation has been observed between symbolic play or pretend play, and language. ${ }^{37}$ Studies prove that developmental aspects of play are significantly linked with early communication and language as well as preoperational and sensorimotor periods of cognitive development. ${ }^{38,39}$ The time, content and structure of symbolic play influence early language development in children. ${ }^{40}$ McCune $^{38}$ emphasized that following the representational development of play, children also undergo language-related transitions, eg, children exhibiting play in a hierarchical combination (filling a bottle and subsequently nursing the doll) even produce syntactic combinations during communication ("I need spoon and plate"). Therefore, $\mathrm{McCune}^{38}$ showed that the development of language and symbolic play have a comparable pattern. Pretend play also has correlations with language, narration, emotional regulation, executive and social functions, reasoning, problem-solving, creativity and intelligence. ${ }^{41}$ Play also provides a conducive environment for word learning. ${ }^{42}$ A predominantly helpful kind of play is adult-led play, in which the adult structures the play environment of the child and in turn helps in supporting a child's learning. ${ }^{41}$ 


\section{Assessment of These Dimensions}

Pre-linguistic skills, communication patterns and play behaviors are effectively assessed in an interaction-based play context with adults. ${ }^{43}$ Some of the methods that have been used for the assessment of parent-child interactions are interactions in natural settings (home, school, etc.), parental interaction in structured environment (laboratory) questionnaires, parental interview-based assessment and video-based analysis. ${ }^{44}$ Video-based analysis has been preferred over other forms of observational analysis, as it is repeatable and practical for offline analysis by multiple observers. ${ }^{45}$ One robust video-based analysis method devised by Tait $^{46}$ has been used successfully to monitor pre-linguistic traits in children wearing amplification devices. The method entails video recording of interactions between an adult and a child in a conversational scenario over time. The study methodically analyzed several aspects of the interactions including auditory processing, eye contact, autonomy and turn-taking. ${ }^{46,47}$

\section{Present Research}

Though the influence of parental roles, communication traits, play behaviors and pre-linguistic skills in early childhood have been recognized in speech and language development of children, little is known through a comprehensive research where pre-linguistic traits, play behaviors and parent-child dynamics have together been explored among children with receptive expressive language disorder. ${ }^{33}$ Parental interaction with their child is largely dependent on the ability to understand their child's behavior, speech or non-verbal expressions. ${ }^{48}$ Children with developmental disabilities are less responsive and have difficulty during parent-child interactions. ${ }^{49,50}$ Besides, parents of these children need the ability to identify and decipher the cues given by their children to respond accurately. Children with developmental disabilities might have socio-communicative deficits which make interactions with their parents difficult. ${ }^{51}$ Understanding the differences between typically developing children and children with receptive expressive language disorder with regard to these domains may provide essential information regarding underlying aspects that need to be strengthened for facilitating age-appropriate speech and language development in CWRELD. Therefore, the present study aimed to explore the differences between certain dimensions of parents, children and play behaviors among Children with Typically Developing Language (CWTDL) and Children with Receptive and Expressive Language Disorder (CWRELD) using a video-based analysis during parentchild interactions. The objectives of this study were (i) to examine the differences in pre-linguistic skills such as turn-taking instances, duration of eye contact and autonomous instances between CWTDL and CWRELD, and (ii) to explore differences, if any, in the proportion of different parental roles, childhood communication stages and play behaviors among CWTDL and CWRELD. The study hypothesized that CWTDL might exhibit a better profile with respect to pre-linguistic skills as compared to CWRELD, ie, demonstrating a higher proportion of turntaking instances, optimum duration of eye contact and higher autonomous instances. With respect to the proportion of different parental roles, childhood communication stages and play behaviors, the study hypothesized that as compared to CWRELD, CWTDL may exhibit a greater proportion of Partner type or the Early communicator type profile along with more instances of symbolic play with their parents demonstrating higher proportion of Partner profile.

\section{Method}

A cross-sectional study design was followed in the present study. The participants were recruited through nonrandom sampling. Approval was obtained from the Institutional Ethical Committee Kasturba Medical College, Mangalore (IEC KMC MLR 05-17/96) for the study protocol, and informed consent was taken from the parents of children who participated in the research. This study was conducted in accordance with the Declaration of Helsinki.

\section{Participants}

Twenty children in the age range of 3 to 6 years were recruited from the outpatient department of a multispecialty hospital. These children and their parents had either Kannada, Malayalam or Hindi as their native language. The participants were divided into two groups with seven males and three females in each group. The first group consisted of 10 children (Mean chronological age- 4.5 years, SD- 0.8 years) who were diagnosed as Children With Receptive Expressive Language Disorder (CWRELD) secondary to inadequate speech and language stimulation as per the standard operating diagnostic protocol of the department which involves expert observations, parental interview and language age determination using standardized measures like Assessment of Language 
Development (ALD).$^{52}$ The second group consisted of 10 Children With Typically Developing Language (CWTDL) (Mean chronological age- 4.4 years, SD- 0.9 years). The two groups of the study were classified into CWRELD and CWTDL based on their receptive and expressive language abilities as obtained using a standardized tool like ALD which ensured that the grouping as per language abilities was accurate. Children with any other physical, behavioral, intellectual or sensorimotor health concerns were excluded from this research. It was ascertained that with respect to the birth order, children from both the groups were "first-born". Since the socioeconomic status of the parents is an important factor that can influence their interactions and in turn the child's communication development, parents belonging to only middle socio-economic status as per the National Socio-Economic Status Scale for Urban Population were included in the study. ${ }^{53}$ This scale considers factors like house, material possession, education, occupation, monthly income, land and social participation and understanding for the determination of socio-economic status. Among the parents, play partners for the current study were selected based on average hours spent by either of them in quality interaction with their child throughout the day. The parent who spent the maximum duration with the child was included as play partner in the current study from the CWTDL group (10 Mothers) and CWRELD group (10 Mothers).

\section{Language Assessment}

For language assessment, the current study used Assessment of Language Development (ALD) ${ }^{52}$ which helped in diagnostic formulations of receptive and expressive language abilities in children. ALD is a standardized, performance-based, norm-referenced test that is used to assess the receptive and expressive language abilities of children from birth to 7.11 years. The present study considered the language age of the child to be the age range just below the ceiling score in both receptive and expressive domains. A ceiling score was obtained when the child produced five consecutive erroneous responses on the test Table 1 depicts the chronological and language age of the study participants.

\section{The Setting for Video Recording}

Parent-child interactions of all participants were video recorded in a conversational setting wherein the parent of the child was instructed to carry out a playful interaction on the floor mat with their child in a quiet, well-lit and distraction-free room for 20 minutes. The parent was told to interact in their routine natural way with the child using

Table I Chronological and Language Age of the Study Participants

\begin{tabular}{|c|c|c|c|c|c|}
\hline Participant & Group & Gender & $\begin{array}{l}\text { Chronological Age } \\
\text { (in Years) }\end{array}$ & $\begin{array}{c}\text { Receptive Language Age } \\
\text { (in Years) }\end{array}$ & $\begin{array}{c}\text { Expressive Language Age } \\
\text { (in Years) }\end{array}$ \\
\hline I & CWTDL & Male & 4.6 & $4-4.11$ & $4-4.11$ \\
\hline 2 & CWTDL & Male & 4.2 & $4-4.11$ & $4-4.11$ \\
\hline 3 & CWTDL & Male & 3.3 & $3-3.11$ & $3-3.11$ \\
\hline 4 & CWTDL & Male & 3.9 & $3-3.11$ & $3-3.11$ \\
\hline 5 & CWTDL & Male & 4.5 & $4-4.11$ & $4-4.11$ \\
\hline 6 & CWTDL & Male & 5.2 & $5-5.11$ & $5-5.11$ \\
\hline 7 & CWTDL & Male & 5.8 & $5-5.11$ & $5-5.11$ \\
\hline 8 & CWTDL & Female & 4.5 & $4-4.11$ & $4-4.11$ \\
\hline 9 & CWTDL & Female & 4.6 & $4-4.11$ & $4-4.11$ \\
\hline 10 & CWTDL & Female & 4.5 & $4-4.11$ & 4-4.1I \\
\hline 11 & CWRELD & Male & 4.6 & $3-3.11$ & $3-3.11$ \\
\hline 12 & CWRELD & Male & 4.2 & $2-2.11$ & $|-| .||$ \\
\hline 13 & CWRELD & Male & 3.3 & $2-2.11$ & $2-2.11$ \\
\hline 14 & CWRELD & Male & 3.9 & $2-2.11$ & $0-0.11$ \\
\hline 15 & CWRELD & Male & 4.5 & $2-2.11$ & $2-2.11$ \\
\hline 16 & CWRELD & Male & 5.2 & $3-3.11$ & $2-2.11$ \\
\hline 17 & CWRELD & Male & 5.8 & $3-3.11$ & $3-3.11$ \\
\hline 18 & CWRELD & Female & 4.5 & $3-3.11$ & $|-| . \mid I$ \\
\hline 19 & CWRELD & Female & 4.6 & $2-2.11$ & $|-| . \mid I$ \\
\hline 20 & CWRELD & Female & 4.5 & $3-3.11$ & $2-2.11$ \\
\hline
\end{tabular}


the age and gender-appropriate toys that were provided to them. Some of the toys made available to the parent included a dollhouse with furniture (including beds, pillows, wardrobes, a sofa and table set, TV set, dining table, and chairs), a kitchen set with utensils, play dough, puppets (hand puppets and finger puppets), soft toys (common animals, fruits and vegetables), puzzles, block set (rectangular, triangular and cubical blocks), toy cars, balls of different size and color etc.

\section{Video Analysis}

The parent-child interaction was video recorded for a total duration of 20 minutes. Generally, in a video-based analysis of parent-child interaction, the early few minutes are spent in understanding the task, initiating it and building appropriate rapport. Few minutes towards the end may get affected by possible fatigue. Therefore, a middle sample of an interaction that has lesser influence of the preparation effect and the fatigue effect is thought to be the most suitable representation of a parent-child interaction. Accordingly, the present research considered the middle 5 min of the 20 min long sample as the suitable representative of the parent-child interaction. ${ }^{54}$ The present study used the Tait video analysis method for assessing preverbal skills in children. ${ }^{46}$ According to this method of video analysis, pre-verbal skills are divided into turntaking, autonomy and eye contact. After the video recording, the complete parent-child interaction was transcribed and coded. A sample of the transcription and the description of the codes has been provided in Appendix 1.

\section{Measures}

\section{Pre-Linguistic Skills}

Three skills, ie, turn-taking, eye contact and autonomy were noted from the parent-child interactions considered during analysis. Two types of turn-taking, ie, turn-taking using silent gestures or signs and turn-taking comprising verbal response (with or without gestures), were identified for analysis. The total number of turns taken by the child was calculated and then a percentage of gestural and verbal turns out of the total turns were computed. Number of syllables for which eye contact was maintained, was noted which included both the span of eye contact with the speaker and the eye contact with the object/toy in the given context. Autonomy was judged based on the number of instances where a child initiated a conversation either with gestures or vocally. Total instances of autonomy were calculated and categorized to compute the percentage of vocal and gestural autonomous instances respectively. The estimation of pre-linguistic skills was jointly done by two researchers by viewing the video samples, transcribing the interaction and coding the data with appropriate symbols. Description of these variables and their symbols is provided in Appendix 1.

\section{Parental Roles}

The instances during the parent-child interaction video sample which corresponded to the specific communicative roles played by the parents were independently observed and classified by two researchers into the Partner role, the Helper role, the Cheerleader role and the Do-Not-Disturb role as per the classification proposed by Sussman. ${ }^{15}$ Description of each of these roles with an example has been provided in Appendix 1. Even one instance of parental behavior, which pointed at any of the four parental roles, was taken into consideration while making the judgment. Since these parental roles are not mutually exclusive, more than one role could be assigned to any parent. In case of any discrepancy, judgment from a third researcher was sought and a decision was made as per the majority.

\section{Communication Stage of Children}

The communication stage of the child as exhibited and observed during the parent-child interaction video sample was independently observed and classified by two researchers into the Own Agenda Stage, the Requester stage, the Early Communicator Stage and the Partner stage as per the classification proposed by Sussman. ${ }^{15}$ Description of each of these stages with an example has been provided in Appendix 1. Even one instance of a child's behavior that pointed at any of the four communication stages was taken into consideration to decide the stage of the child. Since these communication stages are not mutually exclusive, more than one stage could be assigned to any child. In case of any discrepancy, judgment from a third researcher was sought and a decision was made as per the majority.

\section{Play Behaviors}

The play behaviors exhibited by the child were categorized into exploratory play, functional play, symbolic play and constructive play. Play behavior of the child was considered to be exploratory in nature if he/she was found to be aware of the toy in the immediate surrounding and seemed to explore its texture and function through his/her sense of touch, smell or taste. ${ }^{55}$ Play behavior where a child was 
found to appropriately use an object (like using the ball to play catch) or conventionally associate two or more objects (such as placing a cup on the saucer) was noted as functional play. ${ }^{56}$ Symbolic play was considered whenever a child either used an object as if it were another object (like wrapping a piece of cloth as if it was an Indian traditional costume such as saree) or attributed properties to an object which it does not have (using a soft toy as a pillow to rest their head) or referred to absent objects as if they were present (pretending to sip tea from a toy cup). Any play behavior where a child used the toy materials to build something (such as making a block structure using a set of blocks or modeling a figure out of play dough) was considered and noted as constructive play. ${ }^{34}$ Description of each of these play behaviors with an example has been provided in Appendix 1. Even one instance of a play behavior that indicated any of the four play behaviors was taken into consideration to decide the play behavior of the child. Since these play behaviors are not mutually exclusive, more than one play type could be assigned to any child. Play behaviors were independently observed and categorized by two researchers. In case of any discrepancy, judgment from a third researcher was sought and a decision was made as per the majority.

\section{Data Analysis}

The total number of turns, percentage of verbal and gestural turns, span of eye contact (in syllables) to people and objects, total number of autonomous instances along with the percentage of gestural and vocal autonomous moments, parental roles, communication stages and play behaviors were noted and tabulated in Microsoft Excel sheets for participants of both the groups. Descriptive statistics were performed on the study parameters which then underwent Kappa statistic $(\kappa)$ to determine the interrater agreement for the various parameters. Independent $t$-test and chi-square test were used to further examine any between-group differences using a licensed version of SPSS 16.0. A p-value of less than 0.05 was considered to be significant.

\section{Results}

The CWRELD and CWTDL groups having similar chronological age [ $\mathrm{t}(18)=-0.245, \mathrm{p}=0.809]$ were compared for pre-linguistic skills like turn-taking skills, eye contact and autonomy along with parental roles, communication stages of children and nature of their play behaviors.

\section{Differences in Pre-Linguistic Skills Between CWRELD and CWTDL}

\section{Turn Taking}

The analysed video samples of similar duration revealed that CWTDL (M- 45.9, SD- 12.1) exhibited significantly higher number of total turns as compared to CWRELD (M- 19.3, SD- 9.54) [t(18) $=5.439, \mathrm{p}<0.001]$. CWTDL were found to exhibit significantly higher proportion of verbal turns (65.6\%) as compared to CWRELD (47.1\%) while CWRELD exhibited greater proportion of gestural turns $(52.9 \%)$ as compared to CWTDL $(34.3 \%)$ [t $(18)=$ $-3.544, \mathrm{p}=0.002]$.

\section{Eye Contact}

CWTDL were found to maintain significantly longer span of eye contact (M- 564.7 syllables, SD- 126.4 syllables) as compared to CWRELD (M- 365 syllables, SD- 194.1 syllables) $[\mathrm{t}(18)=2.721, \mathrm{p}=0.014]$. CWTDL made significantly longer proportion of eye contact with parents (41.95\%) as compared to CWRELD (18.10\%) while CWRELD made significantly longer proportion of eye contact with objects $(81.9 \%)$ as compared to CWTDL $(58.04 \%)$ [t $(18)=-4.331, \mathrm{p}<0.001]$.

\section{Autonomy}

CWTDL were found to exhibit significantly higher number of autonomous instances (M- 28, SD- 7.1) as compared to CWRELD (M- 21.4, SD- 5.3) [t(18)=2.320, $\mathrm{p}=$ 0.032]. With respect to nature of these autonomous instances, CWTDL were found to have significantly greater proportion of vocal autonomy $(74.5 \%)$ than CWRELD (38.2\%) while CWRELD showed significantly greater proportion of gestural autonomy $(61.76 \%)$ as compared to CWTDL $(25.4 \%)$ [t $(18)=-5.271, \mathrm{p}<0.001]$. These comparisons have been depicted in Figure 1.

\section{Parental Roles Among CWRELD and CWTDL}

Substantial inter-rater agreement was obtained for the parental roles $(\kappa=0.773, \mathrm{p}<0.01)$ among children from both the groups. The distribution of parental roles among the two groups, as shown in Figure 2, revealed that most of the mothers of CWTDL exhibited "Partner role" whereas mothers of CWRELD were mostly of "Helper" type with few exhibiting "Cheerleader" or "Do-Not-Disturb" profile. The proportion of these parental roles was significantly different between the two groups $\left(\chi^{2}=16.571 ; \mathrm{p}<0.001\right)$. 


\section{PRE-LINGUISTIC SKILLS}

100.00

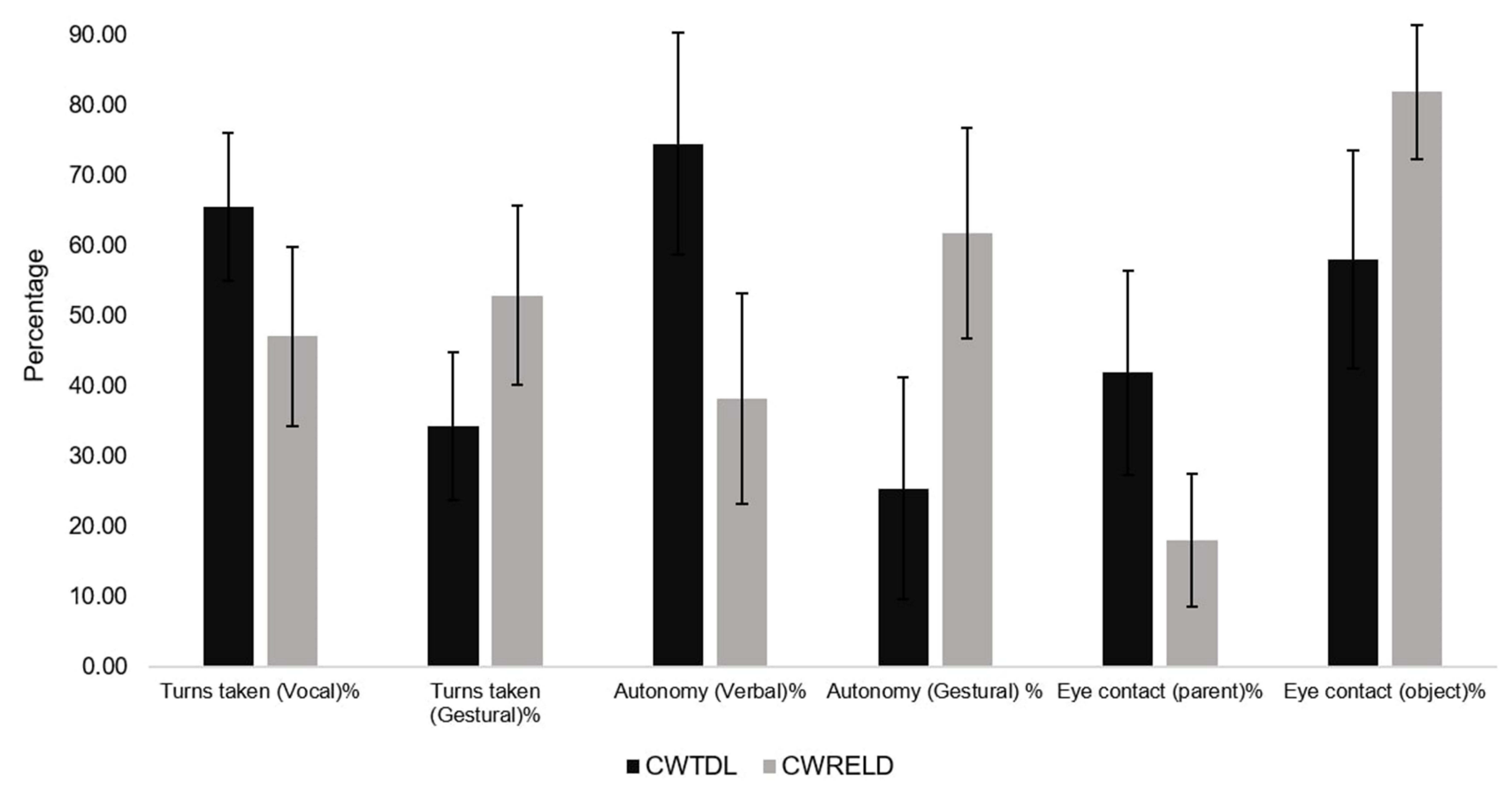

Figure I Differences in pre-linguistic skills among CWRELD and CWTDL. The error bars represent standard deviation.

PARENTAL ROLES

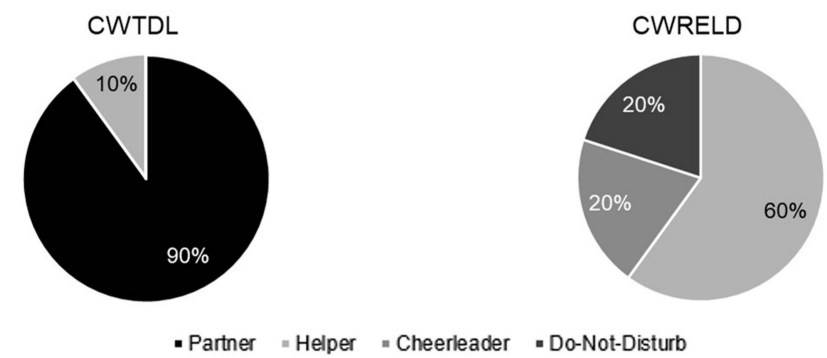

Figure 2 Distribution of parental roles across CWTDL and CWRELD groups.

\section{Communication Stages of CWRELD and CWTDL}

Regarding the communication stages of children from both the groups, substantial inter-rater agreement $(\kappa=0.642, \mathrm{p}<0.01)$ was obtained. The distribution of communication stages exhibited by children, as depicted in Figure 3, revealed that most of the children in the CWTDL group were found to be in the "Partner" stage with a few in the "Requester" stage while children in the CWRELD group were mainly distributed in the "Early communicator", "Requester" and "Own Agenda" stage. The proportion of these communication stages
COMMUNICATION STAGES
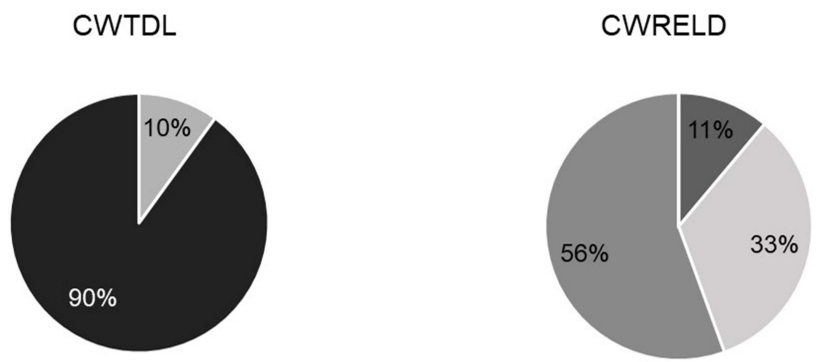

- Own Agenda " Requester " Early Communicator - Partner

Figure 3 Distribution of communication stages across CWTDL and CWRELD groups.

was found to be significantly different between the two groups $\left(\chi^{2}=16.667 ; \mathrm{p}<0.001\right)$.

\section{Play Behaviors of CWRELD and CWTDL}

Unlike the parental roles and child communication stages where only one of these types were identified in the parent or child, one child was found to have presence of more than one type of play behavior. This made an overall estimation of inter-rater reliability inappropriate. 


\section{PLAY BEHAVIORS}

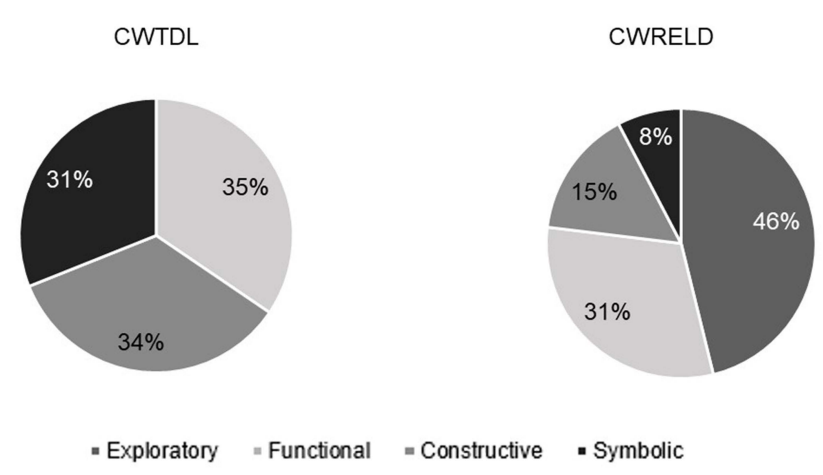

Figure 4 Distribution of play behaviors across CWRELD and CWTDL groups.

Therefore, inter-rater reliability for each play behavior was estimated. Substantial inter-rater agreement was obtained for each play type [Exploratory play $(\kappa=0.588, \mathrm{p}<0.01)$; Functional Play $(\kappa=0.700, \mathrm{p}<0.01)$; Constructive Play $(\kappa=0.700, p<0.01)$ and Symbolic Play $(\kappa=0.700, p<0.01)]$ among children from both the groups. As depicted in Figure 4, the CWTDL group predominately exhibited Functional, Constructive and Symbolic play while most of the children in the CWRELD group demonstrated Exploratory play with a few exhibiting Functional play, Constructive play and Symbolic play. The proportion of these play behaviors was found to be significantly different between the two groups (Exploratory play $\left(\chi^{2}=8.571\right.$, $\mathrm{p}<0.01)$; Functional Play $\left(\chi^{2}=8.571, \quad \mathrm{p}<0.01\right)$; Constructive Play $\left(\chi^{2}=13.333, \mathrm{p}<0.01\right)$ and Symbolic Play $\left.\left(\chi^{2}=12.800, \mathrm{p}<0.01\right)\right)$.

\section{Discussion}

The present research was conducted to explore the differences in parental roles; communication patterns and prelinguistic skills in early childhood; and play behaviors between CWTDL and CWRELD using a video-based analysis of parent-child interactions. The research was carried out with a premise that understanding these differences between the two groups may shed light on fundamental aspects that could be reinforced for enabling ageappropriate speech and language development in CWRELD.

\section{Pre-Linguistic Skills}

The first focus while exploring pre-linguistic skills was on the turn-taking abilities of the children. CWTDL exhibited significantly higher number of turns compared to CWRELD. While CWTDL showed a significantly higher proportion of verbal turns, CWRELD were found to demonstrate a greater proportion of gestural turns. The importance of conversational turn-taking abilities in the speech and language development of children has been well recognized. The quantity and quality of turn-taking skills demonstrated by children are significantly associated with increased brain activation in the areas of linguistic processing. ${ }^{57,58}$ The number of conversational turns taken by children has been reported to be a salient determinant of linguistic abilities later in life. ${ }^{58}$ Similar to the findings of the present research, children with developmental delay like RELD exhibit restricted turn-taking abilities as compared to their typically developing peers. ${ }^{59-61}$ Previous studies have argued that children with developmental delays do not significantly differ from their typically developing peers with respect to communicative intentions, ${ }^{62}$ however, their communicative patterns might be linguistically restricted. ${ }^{60,63}$ To compensate for the linguistic restrictions, children with speech and language delay might resort to non-verbal communicative turns with the usage of gestures, head nods and smiles. ${ }^{63,64}$ This could explain the greater reliance of CWRELD on gestural turns in the present study. Studies have also found that children with delay may develop significant increment in the number of verbal turns, after undergoing intensive speech and language therapy. ${ }^{59}$

With respect to the span of eye contact, CWTDL had a longer proportion of eye contact with parents while CWRELD displayed a longer proportion of eye contact with the objects used during parent-child interactions. Regarding the differences in proportion of eye contact with persons and objects, a study has reported that children with developmental disabilities spent a significantly longer time looking at objects as compared to the people interacting with them. ${ }^{65}$ Exhibiting longer eye contact with objects as compared to persons is reported to be a normal trend observed among typically developing children around six months of age. Therefore, the presence of such a trend among 3-6-year-old CWRELD in this study could hint towards a more premature form of eye contact pattern. The balance between the eye contact with speaker and the object is deemed important to successfully execute joint attention routines which are essential for the development of communication.

Finally, when considering communicative autonomy displayed by the children, CWTDL exhibited greater number of autonomous instances than CWRELD where CWTDL demonstrated higher proportion of vocal autonomy while CWRELD showed greater proportion of 
gestural autonomy. Communicative autonomy has been reported to play a significant role in the speech and language development of children. ${ }^{66}$ Communicative autonomy signifies the ability of the child to initiate a conversation either verbally or through gestures. Similar to the results of the present research, children with developmental delay have been reported to exhibit difficulties in initiating a conversation. ${ }^{67}$ Regarding the nature of these autonomous instances, the findings of the present research coincided with previous studies that have shown that children with developmental delay tend to display greater non-verbal initiatives as compared to their typically developing peers. ${ }^{63,64}$ This has been attributed to linguistic immaturity among children with speech and language delay which compels them to communicate nonverbally. ${ }^{60}$

\section{Parental Roles}

Most parents of CWTDL were found to be Partner type whereas the majority of the parents of CWRELD were Helper Type while some were Cheerleader Type or DoNot-Disturb Type. The transactional model of development speculates that development in children occurs as a result of reciprocal interaction between the parent and the child. ${ }^{7}$ The interactions in turn act as a precursor for motivating parents to increase their verbal responsiveness with their children. This process not only encourages children to learn the language faster but also with minimum effort during the interactions. The parental behaviors during interaction with their children are also known to reflect the kind of parenting practices that they use, which in turn influences the child's self-esteem and development. ${ }^{68,69}$ In the present research, the Partner role taken up by the majority of parents in the CWTDL group is an indicator of the increased responsiveness of parents to children's language attempts, which is a crucial factor contributing to early language learning. ${ }^{70}$ There is evidence suggesting that the way parents of children with delayed speech and language communicate usually gets affected by the communicative and linguistic deficiencies present in their children. ${ }^{62}$ This could explain the helper and cheerleader communicative roles seen among parents of CWRELD in the present study wherein parents help the child to overcome difficulties in communication by providing them appropriate linguistic content, alternative communicative modalities and reinforcements. In a similar context, Rescorla et $\mathrm{al}^{61}$ reported that mothers of children who started talking late in life put an extra effort to sustain a conversation by talking more often. Some parents of CWRELD were also found to be of the Do-not-disturb type where the communicative intent and content exhibited by the parents is found to be limited. These findings are congruent to a study by Hoffner and Bliss $^{71}$ who found parents of children with developmental delay to be less responsive than the parents of typically developing children. A parent may also take the Do-notdisturb role when the child lacks interest in interaction and rarely demands parental attention. Studies have observed that children with disabilities generally tend to produce less readable cues for interactions; they are less responsive during an interaction and respond in fewer predictable ways. $^{49,50}$ If the child's disabilities affect his/her ability to communicate his/her needs, this may pose as a barrier to the parents in correctly interpreting their child's needs and behavior, thereby making the interactions to be less responsive. $^{48}$

\section{Communication Stages}

Most of the CWTDL were found to be in the Partner stage of communication while the communication of the majority of CWRELD was found to be at the Requester stage with some displaying the Early communicator stage or Own agenda stage. CWTDL seem to be at the partner stage as they could demonstrate the usage of ageappropriate linguistic elements and diverse methods of communication to request, protest, greet or draw attention of caregivers to fulfil their needs. Children at this stage can initiate and maintain short interactions and may begin to converse regarding events from the past and future. ${ }^{15}$ The findings suggest that with the limited speech and language resources and skills, CWRELD may have just begun to understand the association between their actions and consequent communicative effect on their parents. These children seem to use ways like pulling or leading the caregiver to the desired object than using advanced linguistic content for the same purpose. Some of them who are transiting to the early communicator stage do seem to indulge in acts of joint attention and begin to use specific gestures, sounds or words to express their needs or regulate their caregiver. However, there still exists a small proportion of CWRELD who are yet to move ahead from an own agenda stage, and the only option their parents have is to observe their body language, gestures, smiles and cries to assume their communicative intent. Different explanations may be used here to understand the communicative profiles of CWRELD. It has been suggested that due to low linguistic profiles, 
children with developmental disabilities tend to rely more on gestural communication than verbalizations. ${ }^{72}$ Some other studies have argued that children with delayed speech and language may possess additional deficits in their social skills. ${ }^{67}$ The reduced linguistic competency along with deficient social skills may explain the reduced motivation and drive among CWRELD to purposefully interact with their partners. ${ }^{67}$ Another viewpoint argues that parents or caregivers of CWRELD fail to understand or respond to the child's pre-intentional initiations, which in turn reduces the meaningful language initiations by the child. $^{73}$

\section{Play Behavior}

Most of the CWTDL were found to exhibit greater instances of Functional, Constructive and Symbolic play as compared to CWRELD who demonstrated more Exploratory play with some displaying Functional and Constructive play and a few showing Symbolic play. Play is a critical milestone that helps the learning and development of children in many ways and is crucial for their overall well-being. ${ }^{74}$ In the present research, CWTDL seem to engage in age-appropriate play as their play was indicative of social and conventional use of an object. $^{75}$ The presence of symbolic or pretend type of play among CWTDL is in accordance with reports suggesting sociodramatic play becoming increasingly common from ages 3 to 6 years. ${ }^{76}$ Such play behavior enables children to initiate and retain communication skills with peers that can promote development of cognition, language and social competence. ${ }^{77}$ Between 3 to 6 years of age, children start showing marked development in their capacity to handle conflicting representation that includes understanding false beliefs, visual perspective-taking and understanding reality in different ways from a different perspective in the play scenario. ${ }^{78}$ The performance of social play strengthens social bonds, enhances social skills, enables children to learn about social exchanges, make friends, reduces aggression, promotes cooperation and encourages reciprocity, altruism, fairness as well as sharing. ${ }^{79}$ On the other side, CWRELD were shown to indulge in more rudimentary play behaviors as compared to their typically developing counterparts. Multiple studies have shown that children with speech and language delays involve in less complicated and depict fewer play behaviors than their typically developing peers. ${ }^{56,80}$ It has been argued that children with developmental disabilities or at a risk for developmental disabilities tend to have delays in play and necessitate the need for intentional systematic instruction to acquire suitable play skills. ${ }^{81}$ Recent evidence in this regard suggests that even when children with developmental delays are given apt materials and free time to engage in play, they are more prone to misuse the objects or materials, use fewer complex behaviors and participate in repetitive behaviors. ${ }^{82}$ This could also explain the large proportion of exploratory play behaviors that were observed among CWRELD in the present research. With respect to the lesser instance of symbolic or pretend play among CWRELD, studies have revealed that children with developmental delays and disabilities cannot often understand and make pretend play actions. ${ }^{83}$

\section{Child, Parent, and Play - Implications of the Findings}

The parental roles and the communication stages of children are known to have a positive influence on the development of children. ${ }^{9}$ Parental interaction must revolve around the interests of the child while providing necessary support and input. ${ }^{84}$ A parent taking a "Partner" type of communicative role ensures that sufficient communicative turns are being taken with the child and the child possesses sufficient opportunities to innovate novel communicative patterns. Educating and empowering parents of CWRELD to make gradual shifts from "Do-not-disturb", "Helper" and "Cheerleader" roles to a "Partner" role may facilitate better communication development among CWRELD. For example, a "Do-not-Disturb" parent may benefit from understanding that a non-verbal denial from a disinterested child might be a better communicative behavior and opportunity than leaving him/her unattended due to his/her linguistic inadequacy. Similarly, a "Helper" parent could be encouraged to be supportive yet have sufficient scope for opportunities for the child to initiate communication. Likewise, a "Cheerleader" parent may benefit from learning a balance between optimum reinforcement and communicative opportunities such that a child does not always feel interrupted in an ongoing interaction. Parents could further be made aware of the different communication stages of their children. The communication development among children could be better facilitated if parents identify various behaviors associated with each communication stage and the transition from one stage to another. For example, appropriate identification of the "own agenda" or "requester" or "early communicator" stage in a child could aid a parent to take desirable 
measures like "following the child's lead in communication", "waiting for child's response" and balancing reinforcement types and intervals'. Since reduced communicative initiations and increased response time of children with delayed speech and language have been reported to influence the type of parental interaction style, a favorable transition of a child's communicative stage may also promote desirable communicative roles among the parents. ${ }^{85}$ It is a challenge for speech and language clinicians to educate and convince the parents of CWRELD regarding the fine aspects of parent-child interaction, plan therapeutic goals in that direction and monitor progress. A quantitative approach of analyzing pre-linguistic skills like turn-taking, eye contact and autonomy of CWRELD might be a promising way of sharing the finer communicative status of the child with the parents, plan goals as well as monitor progress. For example, an increase in verbal versus gestural turns, higher autonomous instances and balanced eye contact (between speaker and objects) during a joint attention routine may indicate some progress with respect to the child's pre-linguistic skills. Assessment of parent-child interaction using a video-based analysis may also help clinicians in framing specific goals with the parents of CWRELD. For instance, parents taking improper turns with the child could be trained to understand and practice the "Observe, Wait and Listen" strategy for an enriched parent-child interaction. A video-guided parental training approach may be used by speech and language clinicians working with CWRELD. Play can also be a significant indicator and facilitator in the present context. Parents should be educated with respect to the child's current play patterns and ways to achieve desirable play behavior. A child transitioning to a "constructive" or "symbolic or pretend" type of play pattern may also display a significant progress in age-appropriate language development.

Though present research offers some relevant insight into several aspects of pre-linguistic skills, parental roles, childhood communication stages, and play behaviors among CWRELD and CWTDL, it does possess certain limitations. The present study could only highlight the distribution of different communication stages, parental roles, play behaviors and pre-linguistic skills among CWRELD and CWTDL. It would have been promising to explore the interaction among these variables which could further provide an insight into the development of communication. Measures like cluster analysis could be considered during future research on larger samples belonging to the two groups, to appreciate existence of certain profiles based on the interactions between these variables. In this research, only mothers of the children from both groups participated during the parent-child interactions. Therefore, these results cannot be generalized to the other parent whose participation and interaction patterns were not analyzed in this research. Also, it remains unclear how interaction patterns and communication roles of more than one caregiver may influence the present findings. Thus, inclusion of both the parents in such studies in future may yield promising insight into communication in children. Also, these findings are restricted to only CWRELD secondary to inadequate stimulation. Future research in this direction may consider other child-related attributes like behavioral deviancies, attention span, parent-related factors like education, employment, etc.

\section{Conclusion}

The present research explored the differences between the pre-linguistic skills, parental communicative roles, communication stages and play behaviors of CWRELD and CWTDL. CWRELD were found to demonstrate lesser proportion of verbal turns, eye contact with the caregiver and verbal autonomous instances as compared to CWTDL. The majority of CWRELD belonged to the "requester" communication stage with most of them indulging in "exploratory" type of play. CWTDL and their parents were observed to be at the "partner" stage of communication and seemed to have indulged equally in "functional", "constructive", and "symbolic" types of play behaviors. Understanding the distribution of these research variables among CWRELD in comparison to CWTDL may help clinicians in planning finer treatment goals, monitoring specific linguistic progress, ensuring better parental participation and achieving better treatment outcomes during language therapy.

\section{Disclosure}

The authors report no conflicts of interest in this work, financial or otherwise.

\section{References}

1. Topping K, Dekhinet R, Zeedyk S. Parent-infant interaction and children's language development. Educ Psychol. 2013;33(4):391-426. doi:10.1080/01443410.2012.744159

2. Hadley PA, Holt JK. Individual differences in the onset of tense marking: a growth-curve analysis. $J$ Speech Lang Hear Res. 2006;49 (5):984-1000. doi:10.1044/1092-4388(2006/071) 
3. Patton OT, Kevin RA, Catherine SE. Home language and literacy environment: final results. - PsycNET. In: Dickinson D, editor. Beginning Literacy with Language: Young Children Learning at Home and School. Paul H Brookes Publishing; 2001:111-138.

4. Page Melissa M, Wilhelm MS, Gamble WC, Card NA. A comparison of maternal sensitivity and verbal stimulation as unique predictors of infant social-emotional and cognitive development. Infant Behav Dev. 2010;33(1):101-110. doi:10.1016/j.infbeh.2009.12.001

5. Watt N, Wetherby A, Shumway S. Prelinguistic predictors of language outcome at 3 years of age. J Speech Lang Hear Res. 2006;49 (6):1224-1237. doi:10.1044/1092-4388(2006/088)

6. Kelly-Vance L, Ryalls BO. Best practices in play assessment and intervention. Best Pract Sch Psychol V. 2004;549-560.

7. Sameroff AJ, Fiese BH. Models of development and developmental risk. - PsycNET. In: Zeanah CHJ, editor. Handbook of Infant Mental Health. The Guilford Press; 2000:3-19.

8. Van Kleeck A, Gillam RB, Hamilton L, McGrath C. The relationship between middle class parents' book-sharing discussion and their preschoolers' abstract language development. J Speech Lang Hear Res. 1997;40(6):1261-1271. doi:10.1044/jslhr.4006.1261

9. Tamis-LeMonda CS, Bornstein MH, Baumwell L. Maternal responsiveness and children's achievement of language milestones. Child Dev. 2001;72(3):748-767. doi:10.1111/1467-8624.00313

10. Marshall J, Goldbart J, Phillips J. Parents' and speech and language therapists' explanatory models of language development, language delay and intervention. Int J Lang Commun Disord. 2007;42 (5):533-555. doi:10.1080/13682820601053753

11. Saracho ON. Family literacy: exploring family practices. Early Child Dev Care. 2002;172(2):113-122. doi:10.1080/03004430210886

12. Silvén M, Niemi P, Voeten MJM. Do maternal interaction and early language predict phonological awareness in 3- to 4-year-olds? Cogn Dev. 2002;17(1):1133-1155. doi:10.1016/S0885-2014(02)00093-X

13. Zeman J, Cassano M, Perry-Parrish C, Stegall S. Emotion regulation in children and adolescents. J Dev Behav Pediatr. 2006;27 (2):155-168. doi:10.1097/00004703-200604000-00014

14. Landry SH, Smith KE, Swank PR, Assel MA, Vellet S. Does early responsive parenting have a special importance for children's development or is consistency across early childhood necessary? Dev Psychol. 2001;37(3):387-403. doi:10.1037/0012-1649.37.3.387

15. Sussman F. More Than Words. Courses.washington.edu. The Hanen Centre; 2012:424.

16. Garcia OF, Serra E, Zacares JJ, Calafat A, Garcia F. Alcohol use and abuse and motivations for drinking and non-drinking among Spanish adolescents: do we know enough when we know parenting style? Psychol Health. 2020;35(6):645-664. doi:10.1080/08870446.2019.1675660

17. Sahithya BR, Manohari SM, Vijaya R. Parenting styles and its impact on children - a cross cultural review with a focus on India. Ment Health Relig Cult. 2019;22(4):357-383. doi:10.1080/13674676.20 19.1594178

18. Darling N, Steinberg L. Parenting styles context: an integrative model. Psychol Bull. 1993;113(3):487-496. doi:10.1037/00332909.113.3.487

19. Krauthamer Ewing ES, Herres J, Dilks KE, Rahim F, Trentacosta CJ. Understanding of emotions and empathy: predictors of positive parenting with preschoolers in economically stressed families. $J$ Child Fam Stud. 2019;28(5):1346-1358. doi:10.1007/s10826-018-01303-6

20. Queiroz P, Garcia OF, Garcia F, Zacares JJ, Camino C. Self and nature: parental socialization, self-esteem, and environmental values in Spanish adolescents. Int J Environ Res Public Health. 2020;17 (10):3732. doi:10.3390/ijerph17103732

21. Fernando G, Enrique G. Is always authoritative the optimum parenting style? Evidence from Spanish families. Adolescence. 2009;44 (173):101-131.

22. Longtin S, Gerber S. Contemporary perspectives on facilitating language acquisition for children on the autistic spectrum: engaging the parent and the child. J Dev Process. 2008;3(1):38-51.
23. Patterson SY, Smith V. The experience of parents of toddlers diagnosed with autism spectrum disorder in the more than words parent education program. Infants Young Child. 2011;24(4):329-343. doi:10.1097/IYC.0b013e31822c10e4

24. Krupa M, Boominathan P, Sebastian S, Venkat Ramanan P. Childdirected communication behaviours during mother-child interaction in children with autism spectrum disorder and typically developing children in south India. Res Autism Spectr Disord. 2019;67 (2018):101423. doi:10.1016/j.rasd.2019.101423

25. Cochet H, Byrne RW. Communication in the second and third year of life: relationships between nonverbal social skills and language. Infant Behav Dev. 2016;44:189-198. doi:10.1016/j.infbeh.2016. 07.003

26. Harbison AL, McDaniel J, Yoder PJ. The association of imperative and declarative intentional communication with language in young children with autism spectrum disorder: a meta-analysis. In: Research in Autism Spectrum Disorders. Vol. 36. Elsevier Ltd; 2017:21-34.

27. Camaioni L, Perucchini P, Bellagamba F, Colonnesi C. The role of declarative pointing in developing a theory of mind. Infancy. 2004;5 (3):291-308. doi:10.1207/s15327078in0503_3

28. Dunham P, Dunham F. Optimal social structures and adaptive infant development; 1995. Available from: https://psycnet.apa.org/record/ 1995-97586-007. Accessed June 23, 2021.

29. Bruner J. Play, thought, and language. Peabody J Educ. 1983;60 (3):60-69. doi:10.1080/01619568309538407

30. Mirenda PL, Donnellan AM, Yoder DE. Gaze behavior: a new look at an old problem. J Autism Dev Disord. 1983;13(4):397-409. doi:10. 1007/BF01531588

31. Baron-Cohen S, Baldwin DA, Crowson M. Do children with autism use the speaker's direction of gaze strategy to crack the code of language? Child Dev. 1997;68(1):48-57. doi:10.2307/1131924

32. Bretherton I. The origins of attachment theory: John Bowlby and Mary Ainsworth. Dev Psychol. 1992;28(5):759-775. doi:10.1037/ 0012-1649.28.5.759

33. Lee K, Schertz HH. Brief report: analysis of the relationship between turn taking and joint attention for toddlers with autism. J Autism Dev Disord. 2020;50(7):2633-2640. doi:10.1007/s10803-019-03979-1

34. Smilansky S. The Effects of Sociodramatic Play on Disadvantaged Preschool Children. 605 Third Avenue, New York, New York 10016 (\$7.50): John Wiley and Sons, Inc.; 1968.

35. Pellegrini AD, Bjorklund DF. The ontogeny and phylogeny of children's object and fantasy play. Human Nature (Hawthorne, N.Y.). 2004;15(1):23-43. doi:10.1007/s12110-004-1002-z

36. Whitebread D, Neale D, Solis L. The role of play in children's development: a review of the evidence; 2018. Available from: https://www.researchgate.net/publication/325171537. Accessed June 23, 2021.

37. Smith LB, Jones SS. Symbolic play connects to language through visual object recognition. Dev Sci. 2011;14(5):1142-1149. doi:10.1111/j.1467-7687.2011.01065.x

38. McCune L. A normative study of representational play at the transition to language. Dev Psychol. 1995;31(2):198-206. doi:10.1037/ 0012-1649.31.2.198

39. Casby MW, Della CM. Symbolic play performance and early language development. J Psycholinguist Res. 1987;16(1):31-42. doi:10.1007/BF01067749

40. Veneziano E. Early language and nonverbal representation: a reassessment. J Child Lang. 1981;8(3):541-563. doi:10.1017/S03 05000900003421

41. Lillard AS, Lerner MD, Hopkins EJ, Dore RA, Smith ED, Palmquist CM. The impact of pretend play on children's development: a review of the evidence. Psychol Bull. 2013;139(1):1-34. doi:10.1037/a0029321

42. Han M, Moore N, Vukelich C, Buell M. Does play make a difference? How play intervention affects the vocabulary learning of at-risk preschoolers. - PsycNET. Am J Play. 2010;3(1):82-105. 
43. Crais ER, Watson LR, Baranek GT. Use of gesture development in profiling children's prelinguistic communication skills. Am J Speech Lang Pathol. 2009;18(1):95-108. doi:10.1044/1058-0360(2008/07-0041)

44. Lytton H. Observation studies of parent-child interaction: a methodological review. Child Dev. 1971;42(3):651. doi:10.2307/ 1127439

45. Sommer A, Hachul C, Roßbach HG. Video-based assessment and rating of parent-child interaction within the national educational panel study. Methodol Issues Longitud Surv Ex Natl Educ Panel Stud. 2016;151-168.

46. Tait DM. Video analysis: a method of assessing changes in preverbal and early linguistic communication after cochlear implantation. Ear Heart. 1993;14(6):378-389. doi:10.1097/00003446-199312000-00002

47. Tait ME, Nikolopoulos TP, Lutman ME, Wilson D, Wells P. Video analysis of pre-verbal communication behaviours: use and reliability. Deaf Educ Int. 2001;3(1):38-43. doi:10.1179/146431501790561106

48. Howe D. Disabled children, parent-child interaction and attachment. Child Fam Soc Work. 2006;11(2):95-106. doi:10.1111/j.13652206.2006.00397.x

49. Marfo K, Dedrick C, Barbour N. Mother-child interactions and the development of children with mental retardation; 1998. Available from: https://scholarcommons.usf.edu/esf_facpub/116/. Accessed June 23, 2021.

50. McCollum J, Hemmeter M. Parent-child interaction intervention when children have disabilities. Eff Early Interv. 1997;549-576.

51. Landa RJ, Holman KC, O’Neill AH, Stuart EA. Intervention targeting development of socially synchronous engagement in toddlers with autism spectrum disorder: a randomized controlled trial. J Child Psychol Psychiatry. 2011;52(1):13-21. doi:10.1111/j.14697610.2010.02288.x

52. Lakkanna S, Venkatesh K, Bhat JS. Assessment of language development. Bak CA Omni Ther Serv. 2008.

53. Tiwari S, Kumar A, Kumar A. Development \& standardization of a scale to measure socio-economic status in urban \& rural communities in India. Indian J Med Res. 2005;122(4):309.

54. Muentener P, Herrig E, Schulz L. The efficiency of infants' exploratory play is related to longer-term cognitive development. Front Psychol. 2018;9(MAY):1-18. doi:10.3389/fpsyg.2018.00635

55. Fenson L, Schell RE. The origins of exploratory play. Early Child Dev Care. 1985;19(1-2):3-24. doi:10.1080/0300443850190102

56. Williams E, Reddy V, Costall A. Taking a closer look at functional play in children with autism. J Autism Dev Disord. 2001;31 (1):67-77. doi:10.1023/A:1005665714197

57. Pepper J, Weitzman E. It Takes Two to Talk: A Practical Guide for Parents of Children with ... - Jan Pepper, Elaine Weitzman, Hanen Centre - Google Books. 4th ed. Hanen Centre Publication; 2004.

58. Romeo RR, Leonard JA, Robinson ST, et al. Beyond the 30-millionword gap: children's conversational exposure is associated with language-related brain function. Psychol Sci. 2018;29(5):700-710. doi: $10.1177 / 0956797617742725$

59. Bortoli A, Brown PM. Assessing prelinguistic communication in children with developmental delay: effects of contextual structure. Australas J Spec Educ. 2000;24(2-3):74-84. doi:10.1017/S1030011 200024751

60. Van Balkom H, Verhoeven L, Van Weerdenburg M. Conversational behaviour of children with developmental language delay and their caretakers. Int J Lang Commun Disord. 2010;45(3):295-319. doi:10.3109/13682820902994226

61. Rescorla L, Bascome A, Lampard J, Feeny N. Conversational patterns in late talkers at age 3. Appl Psycholinguist. 2001;22 (2):235-251. doi:10.1017/S0142716401002053

62. Ellis Weismer S, Davidson MM, Gangopadhyay I, Sindberg H, Roebuck H, Kaushanskaya M. The role of nonverbal working memory in morphosyntactic processing by children with specific language impairment and autism spectrum disorders. J Neurodev Disord. 2017;9(1). doi:10.1186/s11689-017-9209-6
63. Bishop DVM, Chan J, Adams C, Hartley J, Weir F. Conversational responsiveness in specific language impairment: evidence of disproportionate pragmatic difficulties in a subset of children. Dev Psychopathol. 2000;12(2):177-199. doi:10.1017/S0954579400002042

64. Stockman IJ. The new peabody picture vocabulary test-III: an illusion of unbiased assessment? Lang Speech Hear Serv Sch. 2000;31 (4):340-353. doi:10.1044/0161-1461.3104.340

65. Arens K, Cress C, Marvin C. Gaze-shift patterns of young children with developmental disabilities who are at risk for being nonspeaking. Spec Educ Commun Disord Fac Publ. 2005.

66. Wadnerkar Kamble M, Lam-Cassettari C, James DM. Communication skills and communicative autonomy of prelinguistic deaf and hard-ofhearing children: application of a video feedback intervention. Front Psychol. 2020;11:1983. doi:10.3389/fpsyg.2020.01983

67. Paul R, Looney SS, Dahm PS. Communication and socialization skills at ages 2 and 3 in "late-talking" young children. $J$ Speech Hear Res. 1991;34(4):858-865. doi:10.1044/jshr.3404.858

68. Martínez I, Murgui S, Garcia OF, Garcia F. Parenting and adolescent adjustment: the mediational role of family self-esteem. $J$ Child Fam Stud. 2021;30(5):1184-1197. doi:10.1007/s10826-021-01937-z

69. Perez-Gramaje AF, Garcia OF, Reyes M, Serra E, Garcia F. Parenting styles and aggressive adolescents: relationships with self-esteem and personal maladjustment. Eur J Psychol Appl Leg Context. 2020;12 (1):1-10.

70. DeVeney S, Cress CJ, Lambert M. Parental directiveness and responsivity toward young children with complex communication needs. Int J Speech Lang Pathol. 2016;18(1):53-64. doi:10.3109/17549 507.2015.1081282

71. Hoffer PC, Bliss LS. Maternal verbal responsiveness with language-impaired, stage-matched, and age-matched normal children. J Appl Dev Psychol. 1990;11(3):305-319. doi:10.1016/ 0193-3973(90)90012-9

72. Iacono T, Carter M, Hook J. Identification of intentional communication in students with severe and multiple disabilities. AAC Augment Altern Commun. 1998;14(2):102-114. doi:10.1080/07434619812331278246

73. Cress CJ, Grabast J, Burgers Jerke K. Contingent interactions between parents and young children with severe expressive communication impairments. Commun Disord Q. 2013;34(2):81-96. doi: $10.1177 / 1525740111416644$

74. Village G. The importance of play in promoting healthy child development and maintaining strong parent-child. 2007.

75. Casby M. Symbolic play II: a unified model of symbolic play. Infant Toddler Interv. 1991;1:233-243.

76. Smith PK. Play: types and functions in human development. In: Ellis BJ, Bjorklund DF, editors. Origins of the Social Mind: Evolutionary Psychology and Child Development. Guilford Press; 2005:271-291.

77. Nicolopoulou A, Barbosa De Sá A, Ilgaz H, Brockmeyer C. Using the transformative power of play to educate hearts and minds: from Vygotsky to Vivian Paley and beyond. Mind Cult Act. 2010;17 (1):42-58. doi:10.1080/10749030903312512

78. Meins E, Fernyhough C, Arnott B, Leekam SR, de Rosnay M. Mindmindedness and theory of mind: mediating roles of language and perspectival symbolic play. Child Dev. 2013;84(5):1777-1790. doi:10.1111/cdev.12061

79. Graham KL, Burghardt GM. Current perspectives on the biological study of play: signs of progress. Q Rev Biol. 2010;85(4):393-418. doi:10.1086/656903

80. Barton EE. Teaching generalized pretend play and related behaviors to young children with disabilities. Except Child. 2015;81 (4):489-506. doi:10.1177/0014402914563694

81. Thiemann-Bourque KS, Brady NC, Fleming KK. Symbolic play of preschoolers with severe communication impairments with autism and other developmental delays: more similarities than differences. J Autism Dev Disord. 2012;42(5):863-873. doi:10.1007/s10803-011$1317-7$ 
82. Reichow B, Boyd BA, Barton EE, Odom SL. Handbook of Early Childhood Special Education. Springer International Publishing; 2016:1-594 p.

83. Westby CE. A scale for assessing development of children's play. Play diagnosis and assessment. Play Diagn Assess. 2000;2:15-57.

84. Spiker D, Boyce GC, Boyce LK. Parent-child interactions when young children have disabilities. Int Rev Res Ment Retard. 2002;25:35-70.
85. Warren SF, Brady NC. The role of maternal responsivity in the development of children with intellectual disabilities. Ment Retard Dev Disabil Res Rev. 2007;13(4):330-338. doi:10.1002/mrdd.20177

\section{Publish your work in this journal}

Psychology Research and Behavior Management is an international, peer-reviewed, open access journal focusing on the science of psychology and its application in behavior management to develop improved outcomes in the clinical, educational, sports and business arenas. Specific topics covered in the journal include: Neuroscience, memory and decision making; Behavior modification and management; Clinical applications; Business and sports performance management; Social and developmental studies; Animal studies. The manuscript management system is completely online and includes a very quick and fair peer-review system, which is all easy to use. Visit http://www. dovepress.com/testimonials.php to read real quotes from published authors. 